\title{
O LEITOR \\ PRESUMIDO NOS \\ ANÚNCIOS DE CARROS \\ VEICULADOS EM JORNAIS \\ IMPRESSOS DE \\ TERESINA (PI) DE \\ 1950 A 2002
}

\section{EL LECTOR PRESUMIDO EN LOS ANUNCIOS DE COCHES DIFUNDIDOS EN LOS PERIÓDICOS DE TERESINA (PI) DESDE 1950 HASTA 2002}

THE PRESUMED READER IN CAR ADVERTISEMENTS PUBLISHED IN TERESINA'S PRINTED

NEWSPAPERS, FROM 1950 TO 2002

Francisco Alves Filho*

Samarina Soares de Sá**

Universidasde Federal do Piauí

RESUMO: Este artigo pretende demonstrar como a figura do leitor presumido foi construída em jornais impressos da cidade de Teresina (PI), quais sejam: Jornal o Piauí, Jornal Folha da Manhã, Jornal O Dia e Jornal Diário do Povo. Para alcançar esse objetivo, recorreu-se à bibliografia referente aos estudos realizados por autores representantes dos Estudos Retóricos de Gêneros, como Charles Bazerman (2011), Carolyn Miller (2009 [1984]) e Amy Devitt (2004). Além destes, foram utilizados os pressupostos

* Professor do Departamento de Letras e do curso de Pós-Graduação em Letras da Universidade Federal do Piauí. Email: 
bakhtinianos para o estudo do gênero, extraídos, principalmente de Marxismo e Filosofia da Linguagem e de Estética da Criação Verbal, além de autores brasileiros engajados no estudo dos gêneros discursivos, tais como: Fiorin (2008), Marcuschi (2008) e Faraco (2009). Com a pesquisa, foi possível corroborar que os anúncios constituem, de fato, construções histórico-sociais, capazes de espelhar os valores de uma sociedade, mas também de contribuir diretamente para que determinados valores sejam revigorados ou esquecidos.

PALAVRAS-CHAVE: Gênero anúncio; leitor presumido; histórias dos gêneros; anúncio de carros.

RESUMEN: Este artículo tiene como objetivo demostrar cómo el lector presumido fue construido en los periódicos de Teresina (PI), que son: O Piauí, Folha da Manhã, O Dia y Diário do Povo. Para lograr este objetivo, se recurrió a la bibliografía de los estudios realizados por los autores representantes de los Estudios Retóricos de Géneros, como Charles Bazerman (2011), Carolyn Miller (2009 [1984]) y Amy Devitt (2004). Aparte de estos, se utilizan presupuestos de Bakhtin para el estudio del género, tomados principalmente de Marxismo y Filosofía del Lenguaje y de Estética de la Creación Verbal, además de autores brasileños dedicados al estudio de los géneros discursivos como: Fiorin (2008), Marcuschi (2008) y Faraco (2009). Con la investigación, se pudo corroborar que los anuncios son, de hecho, construcciones histórico-sociales, capaces de reflejar los valores de una sociedad, e incluso contribuir directamente a que ciertos valores sean renovados u olvidados.

PALABRAS CLAVE: Género anuncio; lector presumido; historias de los géneros; anuncio de coches.

ABSTRACT: This article aims to present how the image of the presumed reader has been built in the printed newspapers of the city of Teresina (Piaui State, Brazil), with them being the following: O Piauí, Folha da Manhã, O Dia, and Diário do Povo. In order to do so, we have researched the bibliography referent to the studies of authors such as Charles Bazerman (2011), Carolyn Miller (2009 [1984]), and Amy Devitt (2004), representatives of Gender Rhetorical Studies. Besides these, we have consulted Bakhtin's assumptions for studying genre, mainly extracted from Marxism and the Philosophy of Language, and Aesthetics of Verbal Creation, as well as Brazilian authors related to the study of discursive genres, such as Fiorin (2008), Marcuschi (2008), and Faraco (2009). With the research, we could confirm that the advertisements actually build social-historic blocks capable of mirroring the values of a society, but also capable of contributing directly for determined values to be restored or forgotten.

KEY-WORDS: advertisement genre; presumed reader; history of genres; car advertisements.

\section{INTRODUCCÃO}

Os gêneros discursivos são tão antigos quanto o surgimento da humanidade, fato que possibilita reconhecê-los como legítimos representantes da rede comunicativa de que fazemos parte. Afinal, é por meio dos gêneros que solucionamos muitos dos problemas que experienciamos, e, devido a isso, eles estão cotidianamente entre nós, nos permitindo indagar acerca das negociações comunicativas que os permitem atravessar décadas sem perder o cerne de suas características, como sua função social, sua capacidade de dialogizar discursos e de alternar sujeitos em torno de uma mesma atividade linguístico-comunicativa.

É devido a esse caráter social inerente aos gêneros discursivos que se propõe analisar de que maneira o gênero anúncio publicitário foi desenvolvido no Brasil, mais especificamente na mídia impressa (jornal) e voltado para a veiculação de carros, durante o período de 1950 a 2002.

Acreditamos ser importante realizar pesquisas desta natureza, tendo em vista que, por se tratar de construção comunicativa essencialmente desenvolvida na coletividade, a análise de um mesmo gênero, veiculado sob um mesmo suporte, qual seja, o jornal, pode permitir perceber de que forma os arranjos comunicativos são ressignificados no decorrer dos tempos.

A convicção de que os gêneros discursivos são resultantes de um constructo social não deve ser deixada de lado nesta pesquisa. Porém, mais do que reafirmar seu caráter social, o que se propõe aqui é permitir ao leitor perceber de que forma, no decorrer das décadas, a construção dos gêneros discursivos é formulada conforme os acontecimentos de cada período. Ou seja, não basta reconhecer que os gêneros são resultantes de atividades sociais relativamente coordenadas, mas também identificar de que maneira 
os acontecimentos sócio-históricos podem ter contribuído para a flexibilização desses "tipos relativamente estáveis de enunciados" (BAKHTIN, 2003 [1979]).

A fim de se atingir êxito nessa empreitada, propõe-se a análise do leitor presumido encontrado nos anúncios no interstício de sessenta anos, tendo em vista que, por meio da observação dessa categoria será possível identificar de que maneira os publicitários visavam conquistar a atenção do público-alvo.

\section{OS GÊNEROS DISCURSIVOS}

Ao se decidir por analisar o gênero anúncio durante um determinado período histórico, no intuito de visualizar mudanças nele ocorridas, imediatamente, percebeu-se que a natureza deste trabalho está, inevitavelmente, relacionada às atitudes humanas que desencadearam as alterações que aqui serão analisadas. Em nenhuma pesquisa de gênero que se pretenda realizar, a contribuição social deve ser ignorada, já que os gêneros discursivos são resultantes da contribuição de todos que fazem parte de determinado grupo social.

Logo, é possível observar que os gêneros resultam da construção social constantemente realizada por todos nós, fato que leva a considerar os gêneros discursivos como uma construção social. O que se pretende aqui é ressaltar que, sem o caráter social de ações desenvolvidas em torno da linguagem, o uso dos gêneros seria inevitavelmente confuso. Sendo assim, dar-se-á ênfase, aqui, a estudos que se propõem a abordar textos sob uma perspectiva social. Nesse sentido, crê-se que as contribuições advindas de estudos realizados por M. M. Bakhtin e seu Círculo, bem como os estudos realizados por pesquisadores dedicados aos Estudos Retóricos de Gêneros, serão pertinentes para este artigo.

Nesse intuito, utilizamos imagens retiradas no Arquivo Público do Estado do Piauí, mais precisamente dos jornais O Piauí, Folha da Manhã, O Dia e Diário do Povo. Essas imagens foram digitalizadas pelos autores, transcritas e analisadas em busca de enunciados que pudessem nos revelar traços acerca dos leitores presumidos dos anúncios, entre os anos de 1950 aos anos 2000. De posse dessas informações, analisamos os dados juntamente com construções teóricas extraídas de bibliografia de autores que se dedicam ao estudo do gênero, como Bakhtin (2006), Bazerman (2011), Fiorin (2008), Marcuschi (2008), entre outros, com o objetivo de, ao final desta análise, destacarmos quais as principais mudanças ocorridas no que se refere ao público presumido desses anúncios.

\subsection{Sócio-historicidade dos gêneros discursivos}

O aspecto social dos gêneros do discurso está relacionado ao fato de eles serem resultantes de atividades humanas, as quais provocam alterações em sua forma e/ou função, a depender da necessidade dos seus usuários. Tais alterações podem ocorrer tanto na forma como na função dos gêneros discursivos, e podem revelar importantes dados a respeito da maneira pela qual os grupos humanos se apropriam dos gêneros discursivos. É devido a esse caráter social que os gêneros não podem ser tratados de forma alheia à sua realidade sócio-histórica. (MARCUSCHI, 2008).

É por meio da historicidade típica dos gêneros que se pode perceber o quanto os enunciados são atravessados por discursos anteriores, os quais podem surgir tanto explícita quanto implicitamente. Nesse contexto, é válido afirmar que todos os textos estão incorporados a atividades sociais, dependendo, dessa forma, de textos anteriores que exerceram influência sobre a atividade e a organização social (BAZERMAN, 2011). O gênero anúncio, por exemplo, por ser resultante de um construto social, é capaz de ajudar a entender a sociedade na qual ele foi desenvolvido, bem como é capaz de provocar influência em sujeitos sobre os quais atua. Tal influência pode ser suscitada, por exemplo, na maneira pela qual o proprietário de veículos, com determinadas características, pode ser apreciado socialmente em relação àqueles que possuem carros com características outras. Isso ocorre porque a aquisição de carros enseja informações diversas como: grupo social a que pertence, personalidade e estilo de vida. 
A multiplicidade de práticas e de ambientes que podem influenciar os gêneros discursivos se reflete na impossibilidade teórica de se catalogar todos os gêneros que circulam nos mais diversos grupos sociais. Ora, se os gêneros discursivos são resultantes das atividades humanas e, por isso, estão sujeitos a diversas mudanças, é natural que se reconheça a impossibilidade de enumerar todos eles, os quais são infindos por, justamente, serem oriundos das mais diversas práticas interacionais. Para Bazerman (2011, p. 51), jamais será possível alcançar taxionomias estáveis acerca de determinado gênero que satisfaça determinado grupo de pessoas por muito tempo. É devido a essa impossibilidade real de enumeração que muitos estudiosos já desistiram de fazê-lo, visto que, por um lado, esses textos são infinitos, e, por outro lado, porque os gêneros resultam de práticas sociocomunicativas em constante transformação, fato que torna vã qualquer tentativa de listagem definitiva dos rótulos a eles relacionados. (KOCH; ELIAS, 2006).

Certos de que essa atividade de catalogação está fadada ao fracasso, atualmente, a preocupação dos estudiosos do gênero do discurso está voltada, principalmente, para o entendimento dos gêneros enquanto processo sócio-histórico-comunicativo. Dessa forma, hoje, é possível reconhecer que os usuários cotidianos de um gênero são os sujeitos que protagonizam os usos, as mudanças, as permanências, bem como a nomeação dos gêneros (ALVES FILHO, 2011), possibilitando o entendimento de que os gêneros estão inseridos em complexos mundos que são refratados a todo instante por meio das mais variadas atividades de linguagem.

\subsection{Os enunciados na perspectiva de M. M. Bakhtin}

O estudo dos gêneros discursivos perpassa, inevitavelmente, pelo estudo dos enunciados. Bakhtin (2011 [1979]) já asseverava tal proposição ao afirmar que as formas típicas de enunciados nada mais são do que gêneros do discurso (os quais são formados por três elementos indissociáveis, quais sejam: conteúdo temático, estilo e forma composicional). Este autor, ao elaborar sua teoria dos discursos com enfoque social e na atividade dialógica, afirmou que, apesar de os enunciados serem dotados de particularidades, há características recorrentes entre eles. A importância do estudo dos enunciados na teoria bakhtiniana ganha sentido quando se é instigado pelo autor a reconhecer que até mesmo as classificações estilísticas dos textos são tratadas de forma pouco adequada devido ao desconhecimento da problemática que permeia a abordagem dos enunciados.

O autor chama atenção, inclusive, para que sejam mais bem percebidas as mudanças históricas de estilo que acontecem nos enunciados, visto que tais alterações significam mudanças diretamente relacionadas aos gêneros do discurso.

O enunciado se torna, dessa maneira, pedra fundamental dentro da teoria advinda do Círculo de Bakhtin. Se os gêneros do discurso nada mais são do que formas recorrentes e relativamente estáveis de enunciados, então uma precisa explanação a respeito das características do enunciado se torna indispensável para um melhor entendimento da natureza dos gêneros do discurso.

A teoria de Bakhtin e de seus companheiros de Círculo está, sobremaneira, voltada para os aspectos sociais dos enunciados. O caráter prático e concreto é constantemente relembrado pelos autores do Círculo de Bakhtin numa tentativa, quase militante, de não permitir que este aspecto escape aos olhos dos leitores. É preciso focar os aspectos sociais dos textos para que seja oferecido aos seus usuários o reconhecimento de sua participação enquanto sujeitos diretamente responsáveis pelas mudanças ocorridas nesses textos e para que as alterações aí promovidas ganhem significado mais responsivo e dialógico.

Nesse sentido, Bakhtin considera que os enunciados são dotados, basicamente, de três características fundamentais, a saber: alternância dos sujeitos no discurso, conclusibilidade e formas estáveis de gênero do enunciado. O caráter responsivo dos enunciados confere a ele a capacidade de permitir que os sujeitos se alternem durante a comunicação. Para o autor, este caráter está associado apenas aos enunciados, ou seja, orações ou outra forma de unidade de língua jamais suscitarão réplicas, uma vez que a responsividade só ocorre em contato imediato com a realidade. Sendo assim, os enunciados possibilitam relação imediata com discursos alheios, suscitando resposta dos falantes, os quais passam a agir responsivamente na comunicação. 
Cumpre ressaltar que a alternância dos sujeitos, para Bakhtin, é observada numa perspectiva lato (dialógica), de modo que tal aspecto não fique restrito apenas ao diálogo propriamente dito ${ }^{1}$. É por meio do caráter responsivo dos enunciados que emergem as réplicas, as quais constituem as respostas dos interlocutores ao enunciado proferido.

Para Bakhtin (2003 [1979], p. 275), “[...]cada réplica, por mais breve e fragmentária que seja, possui uma conclusibilidade”. Este segundo traço, inerente aos enunciados, está relacionado ao acabamento do dito, fato que permite ao interlocutor replicar a informação enunciada por meio de novos enunciados. A conclusibilidade nada mais é do que a capacidade de o enunciado ser respondido por outro. Em nossas falas existe, segundo Bakhtin (2003 [1979]), um aspecto interno que marca o fim do dito para que outro falante possa replicar a informação anterior. É devido a essa conclusibilidade do enunciado que a alternância dos sujeitos ocorre.

Ainda segundo o autor, a conclusibilidade está relacionada a três elementos que se inter-relacionam: 1) a exauribilidade do objeto e do sentido (que diz respeito à completude do sentido que se deseja expressar) ${ }^{2} ; 2$ ) o projeto de discurso ou vontade de discurso do falante (que diz respeito à percepção, por parte do interlocutor, daquilo que o falante se propôs a comunicar); 3) as formas típicas composicionais e de gênero do acabamento (que diz respeito à maneira pela qual o falante realiza o seu projeto de discurso mediante a escolha do gênero mais tipicamente utilizado em determinada circunstância, ou seja, está relacionado à escolha do gênero mais recorrente na tentativa de solucionar a situação apresentada). Vê-se, portanto, que todos esses aspectos corroboram para um fato em comum: a conclusibilidade é necessária, pois é por meio dela que a alternância acontece, possibilitando a atitude responsiva.

Por fim, as formas estáveis de gênero do enunciado relacionam-se diretamente ao aspecto da conclusibilidade, que trata da escolha realizada pelo falante com o objetivo de reverberar sua intenção comunicativa. Dessa maneira, os usuários optam pela forma típica de enunciado que melhor expresse sua vontade discursiva, uma vez que há a disponibilidade de um amplo repertório de gêneros que são reconhecidos como possíveis de serem usados em determinadas situações. Para Bakhtin (2011 [1979]), os atos enunciativos estão sempre relacionados ao uso de algum gênero. É por isso que, por vezes, são utilizados gêneros em nosso dia a dia sem qualquer suspeita de sua existência. Gênero discursivo para Bakhtin, portanto, é um construto de formas tipificadas de enunciados que são utilizados pelos falantes a fim de responderem, de forma eficiente, às demandas linguístico-comunicativas que emergem nas práticas sociais.

Dentre os aspectos que ajudam a definir o enunciado, diferenciando-o, por exemplo, da oração, Bakhtin destaca, ainda, o atributo da expressividade. Para o autor, é por meio dos enunciados que os usuários manifestam atitudes valorativas. Tais atitudes são inerentes aos enunciados e, sem estes elementos, está-se diante, apenas, de uma oração, visto que a neutralidade predominaria. $\mathrm{O}$ enunciado, ao contrário da oração, não pode ser desprovido de valoração, de expressividade. Para Rodrigues (2005), citando Bakhtin (2011 [1979]), a alternância entre os sujeitos falantes, a expressividade e a conclusividade constituem as principais propriedades que diferenciam enunciado da oração. A oração não estabelece contato direto com a realidade, fato que invalida sua equiparação à instância de enunciado. As orações são, pois, reconhecidas como unidades de língua neutras, já que se trata apenas de uma possibilidade de manifestação concreta da língua, a qual, quando ocorre, passa a ser denominada enunciado.

\subsection{Leitor presumido}

Os gêneros discursivos, conforme se tem visto, são utilizados nas demandas linguístico-comunicativas suscitadas no convívio social. É devido a isso que os gêneros carregam consigo construções sócio-históricas que podem ser constantemente reelaboradas. Por serem inúmeros, os gêneros do discurso necessitam, ainda, de características tanto estáveis como instáveis. A sócio-historicidade dos gêneros demonstra, dessa maneira, que eles são um construto compartilhado e tipificado.

\footnotetext{
${ }^{1}$ Sobre a atividade dialógica e suas implicações, tratar-se-á mais à frente, quando se dedicar uma parte ao estudo das vozes que permeiam os enunciados.

${ }^{2}$ Bakhtin ressalta que a comunicação em si é inexaurível, porém, nos enunciados, dá-se acabamento a ela a fim de permitir que a interação aconteça. Esta pesquisa, por exemplo, apesar de apresentar conclusibilidade enunciativa, possibilita, ainda, diversas indagações que podem reverberar em muitos outros enunciados.
} 
Por ser uma construção cultural compartilhada, os gêneros do discurso suscitam em seus usuários aquilo que se pode chamar de expectativa de entendimento. O termo pode ser mais bem compreendido se for associado à denominação bakhtiniana, que o concebe como auditório social. Auditório social, em Bakhtin e Voloshinov (1976), corresponde à atmosfera em que são construídas as motivações, apreciações e deduções do falante.

Tem-se, a partir daí, que o auditório social diz respeito àqueles para quem a palavra será direcionada, uma vez que a palavra sempre está orientada para outrem. Ou seja, em função da imagem que faz do interlocutor, o falante elabora seu discurso, aprimora-o, e certifica-se de que será entendido, a fim de que possam daí surgirem réplicas outras que desembocarão na interação entre locutor e ouvinte.

Nesse elaborar de discursos, o usuário geralmente leva em consideração a situação social em que a enunciação se desenvolve. Nos dizeres de Bakhtin e Voloshinov (1976) a estrutura da enunciação é determinada tanto pelo contexto social mais amplo como pelo meio social mais imediato e será montada para ser reverberada e assim promover réplicas que permitirão que o ouvinte demonstre compreensão daquilo que foi proferido, corroborando, assim, na concretização da interação.

Tal efeito só é possível ocorrer por meio do entendimento do interlocutor em relação ao dito. Decorre daí o fato de que este ouvinte/leitor presumido precisa ser pressuposto (mesmo que vagamente) para que a enunciação seja dotada de compreensão, pois a palavra é duplamente guiada: de um lado pelo locutor e de outro pelo ouvinte (BAKHTIN; VOLOSHINOV, 1976)

Em Bakhtin e Voloshinov (1976), o leitor/ouvinte presumido é tratado como auditório social. Já em Miller (2009 [1984]), o mesmo significado atribuído à expressão bakhtiniana (auditório social) ganha outra denominação, qual seja: audiência. Esta autora entende que a utilização de enunciados presume que o usuário conheça aquele para quem sua construção enunciativa se dirige. Sendo assim, a audiência corresponde àqueles que irão antecipar, sentir-se gratificados ou que irão responder de uma certa maneira ao que foi dito (MILLER, 2009 [1984], p. 34).

Numa perspectiva literária, Umberto Eco (1979) ressalta a importância do leitor (o qual denomina leitor-modelo), afirmando que ele também é responsável pela construção de sentido de determinada obra, ou seja, não basta apenas a compreensão do autor-texto ${ }^{3}$ para que a produção literária seja bem interpretada. O leitor também se constitui como peça importante nesse jogo de significados. Para Eco (1979), o leitor-modelo diz respeito àquele pensado pelo autor no momento de sua criação, o qual, obviamente, não se confunde com o leitor empírico de determinada obra.

Assimilando tais pressupostos para o que aqui se pretende analisar (anúncios de carros numa perspectiva sócio-históricocomunicativa, aliada à teoria retórica de gêneros discursivos), pode-se dizer que o leitor-modelo pode estar relacionado ao que os publicitários denominam público-alvo. Talvez seja com base nesse aspecto que os anúncios sejam desenvolvidos (tanto texto, quanto imagem, diagramação e demais elementos que a compõem).

Vê-se, portanto, que o leitor/ouvinte é sempre considerado no ato de construção/utilização de uma enunciação ou de um gênero. Alves Filho (2005, p. 55-56), citando Bakhtin e Voloshinov (1976), afirma que o ouvinte é sempre imanente, visto que está sempre sendo refletido pelo usuário, a fim de permitir a melhor fluência da comunicação. Sendo assim, o ouvinte deixa de ser considerado uma entidade externa para ser reconhecido como participante imanente.

Corroborando tais assertivas, Bazerman $(2011$, p. 30) se posiciona afirmando que

[...] se percebermos que um certo tipo de enunciado ou texto funciona bem numa situação e pode ser compreendido de uma certa maneira, a tendência é falar ou escrever alguma coisa também similar. Se começamos a seguir padrões comunicativos com os quais as outras pessoas estão familiarizadas, elas podem reconhecer mais facilmente o que estamos dizendo e o que pretendemos realizar.

${ }^{3}$ Perspectiva de interpretação literária que coloca o autor ou o texto no cerne do processo de interpretação. Nessa perspectiva, a função do leitor é apenas decodificar o sentido já dado. (SANTOS, 2007) 
O que Bazerman (2011) atesta, portanto, é que a escolha dos enunciados ou dos gêneros discursivos visa à compreensão ativa e responsiva do falante. É devido a isso que as formas tipificadas são, geralmente, utilizadas nos contextos comunicativos, já que o usuário presume o tipo de ouvinte/leitor a que se refere, bem como pode se antecipar às suas reações.

\section{O GÊNERO ANÚNCIO: CARACTERÍSTICAS E FUNCIONAMENTO}

O discurso publicitário, dentre os discursos apregoados por Aristóteles, poderia ser relacionado ao que o filósofo grego denomina de discurso deliberativo. A semelhança entre os anúncios e o discurso deliberativo ocorre devido ao fato de este ressaltar o "porvir", uma ação futura, fato que também é exercido por meio daquelas. Os anúncios são elaborados com vistas a permitir que o leitor/ouvinte sinta-se seduzido a agir no futuro e a adquirir, por consequência, aquilo que foi anunciado. Junte-se a isso o fato de que o discurso deliberativo também visa ao convencimento, mediante um aconselhamento, o qual pode reverberar na decisão de consumir algo, mediata ou imediatamente.

Quando se fala em anúncios, imediatamente se remete a mais uma das formas que o homem inventou para se expressar. Os anúncios fornecem informações diversas sobre o grupo em que foram desenvolvidas, expressam comportamentos, vendem ideias, além de serviços e mercadorias.

Para tentar convencer os consumidores a adquirirem determinado produto, os publicitários utilizam técnicas diversas que vão desde a coleta de informações acerca do denominado público-alvo, até o conhecimento sobre a diagramação, a composição da marca, do título e da assinatura.

Segundo Martins (1999), é necessário que as empresas responsáveis pela criação das campanhas conheçam bem o público que pretendem atingir. $\mathrm{O}$ conhecimento do perfil do consumidor permite que as empresas descubram em que diagramação apostar, qual o léxico que pode compor o enunciado do anúncio, bem como escolher o melhor local para ser instalado um estabelecimento, além de tantos outros detalhes que fazem a diferença quando o anúncio é veiculado. Para ele:

[...] sabemos que é quase impossível para uma empresa ou instituição de qualquer gênero procurar atender a absolutamente todas as pessoas ao mesmo tempo e em todos os lugares. Por isso, as empresas e instituições segmentam seus públicos de interesse em categorias como idade, sexo, renda, religião, localização etc. Automóveis de luxo são oferecidos a pessoas de ambos os sexos, de alto poder aquisitivo e moradores das maiores cidades. Pouco provável encontrar-se um revendedor de BMW no interior do Acre. (MARTINS, 1999, p. 40)

De posse de informações a respeito do público consumidor, as empresas viabilizam estratégias para conquistá-lo, fazendo uso de técnicas, as quais, geralmente, remetem para o esquema que será reproduzido a seguir, o qual foi formulado por Durandin (1997).

De acordo com este autor, as ações em torno de um objeto de consumo são determinadas por dois fatores: "[...] de um lado, nossos desejos; de outro, as informações de que dispomos quanto aos meios para realizar esses desejos” (DURANDIN, 1997, p. 24). Com base nestes dois fatores, Durandin elaborou o esquema a seguir: 


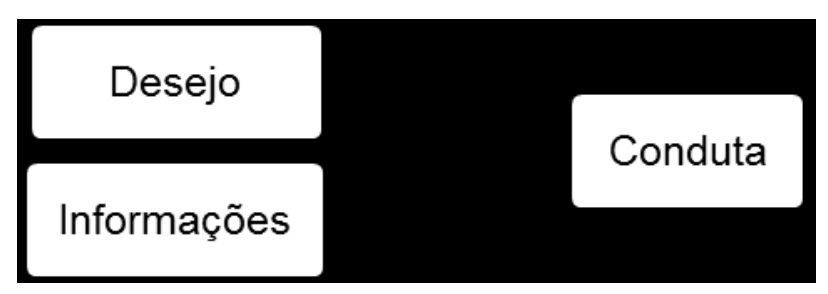

Figura 1: Esquema de conduta do consumidor Fonte: Durandin (1997, p. 24)

Imagine-se uma situação hipotética na qual um indivíduo deseje trocar seu aparelho celular. A partir desse desejo, o indivíduo passa a pesquisar em quais operadoras poderá encontrar o celular que mais lhe agrada. A partir de então, ele passa a observar com mais atenção os anúncios que são veiculados sobre a comercialização de telefonia móvel.

Com base em todas as informações que lhe foram apresentadas, ele poderá agir de forma a satisfazer seu desejo inicial, ou seja, sua conduta será a de optar por um modelo X de aparelho celular.

É certo, pois, que as informações tentam direcionar o comportamento dos consumidores, já que, quando o desejo for suscitado, ele recorrerá àquela empresa que se utilizou dos melhores argumentos e atrativos para persuadi-lo.

Cada instituição, portanto, de caráter comercial ou não, procura conhecer o perfil de consumo e/ou interesses pessoais e tenta convencer os consumidores de que seus produtos, serviços e ideias são adequados e necessários para a satisfação desses interesses. (MARTINS, 1999, p. 39)

\section{A RECORRÊNCIA DO LEITOR PRESUMIDO EM ANÚNCIOS}

O público-alvo, aquele para quem a mensagem propagandística se dirige, faz muita diferença na construção de um anúncio. Aquele em torno do qual a mensagem é elaborada precisa ser adequadamente interpretado pelos desenvolvedores dos anúncios. O objetivo é cativar sua atenção de modo a permitir que ele se sinta motivado a consumir e a reverberar de forma positiva as marcas.

O público-alvo acima referido pode ser igualmente denominado leitor presumido. Viu-se (em 1.3) que o leitor presumido [denominado auditório social, em Bakhtin (2012); audiência, em Miller (2009); e leitor-modelo, em Eco (1979)] corresponde àquele para quem, de forma generalizante, é voltada uma informação. Em se tratando de anúncios, o estudo desse público é a condição de sobrevivência de uma marca, afinal, pouco êxito terá uma marca que sequer sabe a que público se dirige. Dessa forma, é necessário entender para quem se está falando, a fim de que a comunicação se estabeleça da maneira mais direta possível, pois, conforme se tem visto nesta pesquisa, o anúncio não é o gênero predileto de quem se propõe a se debruçar sobre um jornal ou uma revista, e, por isso, torna-se necessário, portanto, elaborá-la de forma a seduzir os leitores e convencê-los de seus benefícios. Sendo assim, quanto maior entendimento for possível obter do leitor presumido, maiores as chances de ele ser cativado para a mensagem apresentada.

Nos anúncios de carros analisados, foi possível identificar que o leitor presumido foi interpretado de duas maneiras mais predominantes, mas cada uma num momento histórico diferente: ora como um público abastado; ora como um público que aqui se poderia incluir na chamada Classe Média.

Neste trabalho, a classe média é entendida como aquela que se moldou no Brasil a partir da década de 50 e, notadamente, nos anos 70. Para Gomes (2005, p. 2), “[...] no Brasil, o crescimento econômico e a complexificação da estrutura produtiva propiciaram o 
surgimento de uma classe média urbana numerosa”, concentrada, sobretudo, no setor de serviços e no emprego público (BALTAR et al., 1996, p. 89 apud GOMES, 2005, p. 4). Essa classe é caracterizada por um poder de compra não apenas concentrado em itens necessários à sobrevivência, uma vez que possui poder aquisitivo razoável para consumir, também, lazer e cultura. Não se trata, portanto, de detentores de padrão de vida demasiado alto (como o público abastado), mas de representantes de uma classe que, atenta às suas peculiaridades, insere-se no panorama econômico brasileiro, de modo a se tornar, inclusive, público-alvo de anúncios de carros.

Dessa forma, nos anúncios analisados, a predileção pelo público abastado fica evidente na construção dos enunciados que compõem as primeiras décadas do corpus desta pesquisa (décadas de 50, 60 e 70). No exemplo que se segue (Jornal O Piauí, 6 de novembro de 1952), é possível observar a maneira pela qual o publicitário se refere ao leitor presumido. Veja-se:

(A1) ANÚNCIO AUSTIN A-40. Jornal O Piauí, Teresina, 6 nov. 1952.

\author{
AUSTIN A-40. \\ qualidade da indústria automobilística inglêsa. \\ Estabelecimentos JAMES FREDERICK CLARK S.A. \\ PRAÇA DEODORO, 20 TERESINA-PIAUÍ
}

A Casa Inglesa acaba de receber novos embarques do famoso Austin A-40. O Sr. está convidado a examinar este magnífico carro, que representa o novo padrão de confôrto, economia, beleza e

A partir do exemplo supra, é possível identificar que o leitor do anúncio é denominado de Senhor. A opção pelo uso de pronome de tratamento mais distintivo sugere que o público desse automóvel não poderia ser constituído, a princípio, por grupos sociais menos privilegiados, tendo em vista, inclusive, os altos preços cobrados pelos veículos comercializados. Tal entendimento parece ser confirmado pelas descrições apresentadas sobre o veículo, tais como novo padrão de conforto, economia, beleza e qualidade da indústria automobilística inglêsa. Trata-se, portanto, de um importado cujos compradores estavam restritos, a priori, a consumidores dotados de condições sociais mais favorecidas ${ }^{4}$, e a escolha pelo tratamento conferido a esse público, de certa forma, determina o grupo social para o qual foi escolhido. Também há a orientação, através da escolha pelo pronome de tratamento masculino senhor, em relação a um público masculino.

O mesmo público é ressaltado em outras ocorrências deste corpus. Entretanto, não mais pelo uso do tratamento Senhor, mas pelas descrições do veículo apresentadas. Nos casos abaixo, é possível identificar outros cinco trechos de ocorrências desse tipo de mensagem. Vejam-se os casos que se seguem:

(A2) ANÚNCIO AERO-WILLYS. Jornal O Piauí, Teresina, 7 mai. 1961.

Quatro portas, amplo espaço interno para acomodar folgadamente seis pessoas. Porta-malas espaçoso. Côres modernas. Luxuoso acabamento interno.

(A3) ANÚNCIO ASTRO. Jornal Folha da Manhã, Teresina, 1 set.1961.

\title{
CHEGOU O NÔVO ASTRO
}

Já está em nossa loja o novo astro da indústria automobilística brasileira - o Aero-Willys 2600 - que estabelece uma superclasse em matéria de automóvel. Venha ver seu estilo arrojado, em harmonia com as linhas clássicas dos carros modernos. Observe e admire sua elegância e o 645ara645go645

\footnotetext{
${ }^{4}$ Ressalta-se, contudo, que o leitor presumido, como a própria denominação sugere, refere-se ao público que é apenas pressuposto, visto que os leitores reais podem ultrapassar a fronteira daquilo que foi inicialmente presumido. Ou seja, a expectativa de leitores seria, dessa forma, representada pelos leitores presumidos, enquanto aqueles que, de fato, tiveram acesso à mensagem são os denominados leitores reais.
} 
que êle oferece. Você se convencerá de que o Aero-Willys 2600 é o mais luxuoso e perfeito carro de classes até hoje produzido no país.

(A4) ANÚNCIO ASTRO. Jornal Folha da Manhã, Teresina, 8 out.1963.

\title{
AÍ VEM O NÔVO ASTRO
}

\section{AEROWILLYS 2600}

Você está convidado a vir conhecê-lo em nossa loja, para admirar a beleza do seu estilo sóbrio em harmonia com as linhas clássicas dos carros modernos e para certificar-se de que êle realmente firma novos padrões de elegância, luxo e perfeição.

(A5) ANÚNCIO AW 2600. Jornal Folha da Manhã, Teresina, 10 out. 1963.

a maior sensação é o AW 2600

ONDE QUER QUE SURJA O AERO-WILLYS 2600 É ALVO DAS ATENÇÕES. É O CARRO DE CLASSE MAIS COMENTADO HOJE NO BRASIL. TORNOU-SE PREFERIDO E DISPUTADO PORQUE É O MAIS CONFORTÁVEL, SEGURO E LUXUOSO. SUAS LINHAS MODERNAS, A BELEZA DO ESTILO SÓBRIO E ELEGANTE E A EXTRAORDINÁRIA PERFEIÇÃO MECÂNICA FIZERAM DO AERO-WILLYS 2600 DE 110 H.P.

(A6) ANÚNCIO VEMOSA. Jornal O Piauí, Teresina, 26 e 27 jan. 1972.

\section{VENHA BUSCAR O SEU NÔVO CARRÃO DE VISITAS}

Quer tranquilidade, quer segurança, quer sossêgo na vida. É carrão pra v. se apresentar nos lugares mais refinados, mais exclusivos. Nossos planos, nossas condições, nosso jeito de tratar os amigos também são nosso melhor cartão de visita.

\begin{abstract}
Os trechos negritados dos enunciados dos anúncios revelam a adjetivação apresentada aos modelos propagandeados: 'luxuosos', 'elegantes' e 'refinados' são alguns dos termos utilizados para se referir a esses modelos. Vê-se que não se trata de uma mensagem construída para qualquer grupo social. Trata-se de textos elaborados com o propósito de conquistar a atenção dos grupos mais abastados, a fim de que pudessem se convencer da sofisticação de que iriam usufruir caso adquirissem, por exemplo, um veículo para "se apresentar nos lugares mais refinados, mais exclusivos" (A6).

Tais discursos, entretanto, não corresponderam à maior recorrência identificada nas vinte e quatro anúncios de carros que compõem o corpus deste estudo, uma vez que, no universo das 24 imagens, em 18, observou-se que os anúncios não estavam mais voltados à pequena fatia de consumidores economicamente mais privilegiados, visto que, a partir da década de 70, outros segmentos passaram a fazer parte do público-alvo dos anúncios, já que a aquisição de veículos não estava mais restrita à chegada dos importados em território nacional, pois o Brasil, além de já produzir seus próprios veículos, assistia à participação de outros segmentos sociais como potenciais consumidores de veículos, ou seja, os discursos que antes enfatizavam o glamour adquirido com a aquisição de alguns modelos cederam espaço para a construção de enunciados mais coloquiais, com o claro objetivo de atingir o novo grupo consumidor que se erguia (a Classe $\mathrm{C})^{5}$, conforme se vê a seguir:
\end{abstract}

5 Classe C: no Brasil, classe social detentora de poder aquisitivo razoável, sobretudo a partir da década de 70 (GOMES, 2005), que passa a ser público-alvo de anúncios de carros elaborados com linguagem e características persuasivas que perduram, em se tratando desta pesquisa, até o ano de 2002. 
(A7) ANÚNCIO VARIANT. Jornal O Piauí, Teresina, 1,2 e 3 jan. 1972.

Venha logo buscar a sua nova Variant, porque tem muita gente apaixonada por ela.

É gente que não acaba mais. Disposta a tudo pra levar a nova Variant. Veja só o que êles comentam aqui na loja: "Puxa! Como a Variant ficou bonita com essa nova frente." "Queridinho, v. já imaginou se a gente tivesse êsse carro e pudesse sair com as crianças todo fim-de-semana, para bem longe desse barulho?" "Nossa! E vem com pisca-piscas embutidos no para-choque da frente." "Vocês precisam é ver a Variant numa estrada." "O que êsse carro tem de bom mesmo é que êle é Volkswagen.” “Claudinho, tira a mão da pintura senão o môço fica bravo.” "Tá aí no folheto: 65 H.P., 2 carburadores e freios a disco." "Eu ainda vou levar essa coisa linda pra nossa garagem." "pois não, aceito um cafezinho."

VERMOSA REVENDEDOR AUTORIZADO VOLKSWAGEN

O diálogo proposto no exemplo supramencionado, por apresentar traços de informalidade, sugere que os leitores presumidos desse anúncio não mais seriam os representantes dos grupos sociais abastados, e, sim, consumidores economicamente menos favorecidos e dispostos apenas a adquirir segurança e praticidade, ao invés de aceitação por parte de seus pares. O mesmo acontece no exemplo que se segue:

(A8) ANÚNCIO NOVATERRA. Jornal Diário do Povo, Teresina, 5 mai. 1994.

Ao meu filhinho querido, amado, idolatrado da mamãe... Passe na Novaterra e escolha entre esses modelos, o presente que jamais esquecerei.

SE VOCÊ DESEJA CONTINUAR SENDO O QUERIDINHO DA MAMÃE, APRAREÇA NA NOVATERRA ATÉ SÁBADO E LEVE PARA ELA, UM PRESENTE DE VALOR. PREÇOS ESPECIAIS TAMBÉM PARA OUTROS MODELOS.

GOL - A PARTIR DE 9.900 URVs.

PARATÍ - A PARTIR DE 12.000 URVs.

Logus - a partir de 15.000 URVs.

SANTANA - A PARTIR DE 21.700 URVs.

Novaterra: aqui você faz o melhor negócio.

Aqui, tem-se um exemplo de anúncio parcialmente criado no formato de outro gênero, qual seja: o bilhete. Neste caso, o publicitário fez uso da intergenericidade, tendo em vista que utiliza a forma de um gênero (bilhete) a fim de corroborar a função de outro (anúncio). No enunciado acima, observa-se que, assim como o proposto no exemplo (A7), a linguagem coloquial indica que não apenas leitores de um grupo social previamente considerado mais dotado financeiramente se sentirão escolhidos pelo texto, haja vista que, por sua linguagem informal, o texto pode atingir público de grupos sociais distintos.

A tendência observada nos exemplos supra (A7 e A8) é frequente em mais 16 ocorrências, ou seja, a ênfase em aspectos mecânicos e financeiros prevalece, ao contrário das ocorrências dos exemplos A2 a A6, os quais enfatizavam a apreciação social atribuída à aquisição do veículo, distinguindo, assim, os leitores presumidos, uma vez que a aquisição de carros de luxo pressupõe um público menos "popular". Tal recorrência pode ser mais bem compreendida se se considerar que em A7 e A8, por exemplo, o momento histórico vivenciado pelo Brasil já permitia que os segmentos sociais, antes pouco valorizados como potenciais compradores de veículos, passassem a ser inseridos nesse setor, permitindo que o estilo dos anúncios do início da década de 50 não recorressem como antes. Quer dizer, o público mais abastado (caracterizado por poder de compra menos limitado, em relação à classe C), enfatizado nos anúncios da década de 50 (momento em que a aquisição de veículos não era prática comum entre os economicamente menos favorecidos), deixou de ser o mais visado na construção dos materiais propagandísticos, uma vez que outro segmento (a Classe C, numerosa fatia de mercado a ser explorado no Brasil, com poder aquisitivo capaz de investir, razoavelmente, 
em lazer e cultura [GOMES, 2005, p. 4]) começava a se afirmar economicamente como detentora de salários capazes de subsidiar a compra de veículos.

Sendo assim, chega-se à conclusão de que o leitor presumido recorrente dos anúncios veiculados a partir da década de 70 corresponde ao que aqui se tem denominado Classe $C$, visto que esses representantes da renovação da base da pirâmide social brasileira, dada sua quantidade mais significativa, passaram a constituir importante fatia do mercado automobilístico, tendo em vista a popularização de modelos desenvolvidos na indústria nacional e o avanço desse mercado em território brasileiro, o qual pode ser confirmado caso se observe que até mesmo os slogans preconizavam o desenvolvimento da indústria brasileira de automóveis, conforme se pode observar a seguir, com o slogan "o grande carro brasileiro".

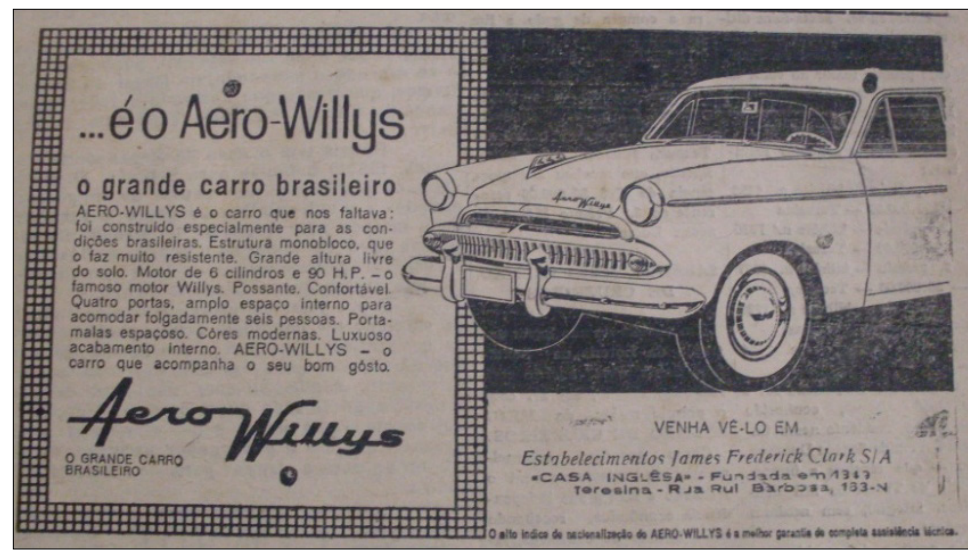

Figura 2: Anúncio Aero-Willys

Fonte: Jornal O Piauí, 7 de maio de 1961

O apelo para a venda de importados como símbolo de luxo e elegância deixou de ser constante nos anúncios a partir do momento em que a própria indústria nacional vai se firmando com a construção de montadoras em nosso território. É o que se pode observar com a figura abaixo, a qual, em nenhum momento, utiliza símbolos sociais como elementos de persuasão; pelo contrário, nesse anúncio predomina o apelo a condições de financiamento e a aspectos como segurança e a ausência de multas. Além disso, o leitor presumido, anteriormente denominado senhor, passa a ser substituído por você, fato que nos leva a entender que os criadores desses anúncios começam a prezar por uma relação de maior proximidade com o leitor, eliminando, assim, a barreira mais formal acarretada pelo uso do tratamento senhor.

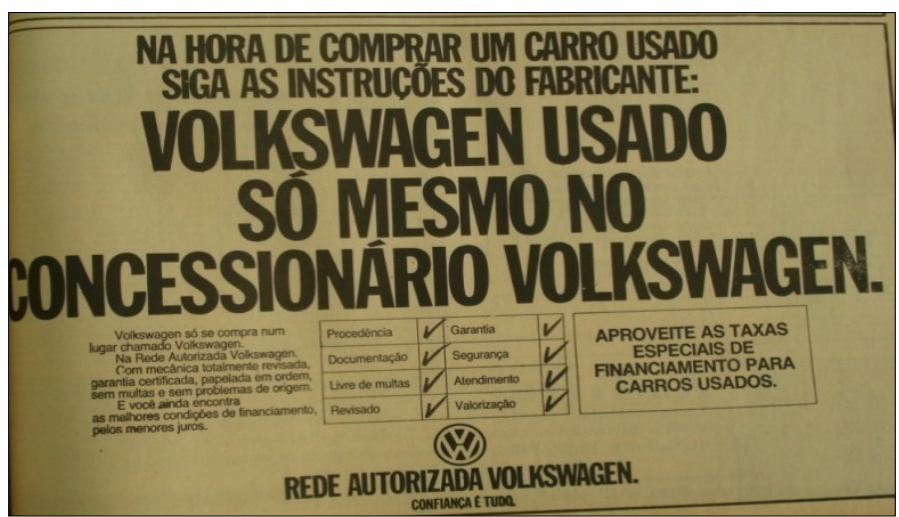

Figura 3: Anúncio de financiamento de modelos de carros Volkswagen Fonte: Jornal O Piauí, $1^{\circ}$ de dezembro de 1981 
O Plano de Metas de Juscelino também permitiu que o setor automobilístico se multiplicasse no Brasil. Segundo Priore e Venâncio (2001), em curto prazo, o Plano atingiu estrondoso sucesso, elevando as taxas de crescimento a 10\%. Nesse ínterim, as rodovias são multiplicadas e o incentivo à produção nacional é intensificado.

Tudo isso é reverberado na predileção dos desenvolvedores dos anúncios pelo público consumidor que se formava. A Classe C, atenta sobretudo a condições de financiamento e não apenas a requinte e luxo advindos da aquisição dos veículos, passa a ser aquela para quem os anúncios mais se dirigem, com linguagem direta e com ênfase em preços e condições técnicas dos carros, tais como nos exemplos abaixo:

(A9) ANÚNCIO NOVATERRA. Jornal O Dia, Teresina, 12 mai. 2002.

Tudo que é sucesso se repete!

MEGA Feirão Novaterra 2

Gol Special Free a vista por apenas $\mathbf{R} \$ \mathbf{1 4 . 6 5 0}$

Ou financiado com taxa a partir de 0,98\% a.m.

Toda linha com de entrada $0 \%$

48 meses para pagar + emplacamento e tanque cheio grátis!

Super Plantão de Vendas

De segunda a sexta até as $20 \mathrm{~h}$ Sábado até as $18 \mathrm{~h}$

Teresina Av. João XXIII, 3480 Tel.: 232-1311

Novaterra: O revendedor da gente.

novaterra@webone.com.br

(A10) ANÚNCIO GOL. Jornal O Dia, Teresina, 21 mai. 2002.

\section{ÚLTIMO DIA DA PROMOÇÃO}

Gol Special Free de R \$ 14.650, por apenas R\$ 13.990,

Toda linha com $0 \%$ de entrada e 48 meses para pagar.

Super Plantão de Vendas

De segunda a sexta até as $20 \mathrm{~h}$ Sábado até as $18 \mathrm{~h}$

Teresina Av. João XXIII, 3480 Tel.: 233-7070

Novaterra: O revendedor da gente

novaterra@webone.com.br

Ressalta-se, ainda, que o uso de termos como "Feirão" e a apresentação de preços e vantagens em letras garrafais e coloridas (tais como: por apenas $R \$ 14.650$, toda linha com $0 \%$ de entrada, tanque cheio grátis! e por apenas $R \$ 13.990$ ) confirmam que a mensagem publicitária está, sobretudo, voltada para consumidores que desejam muito mais economizar do que "ostentar", como podemos conferir a seguir (Figuras 4 e 5). Ou seja, o leitor presumido aqui é alguém que detém pouco dinheiro e que acreditará estar fazendo um bom negócio pelo fato de poder comprar um produto barato, sem comprometer o seu reduzido orçamento e ainda sendo agraciado com brindes (emplacamento e tanque cheio grátis). 


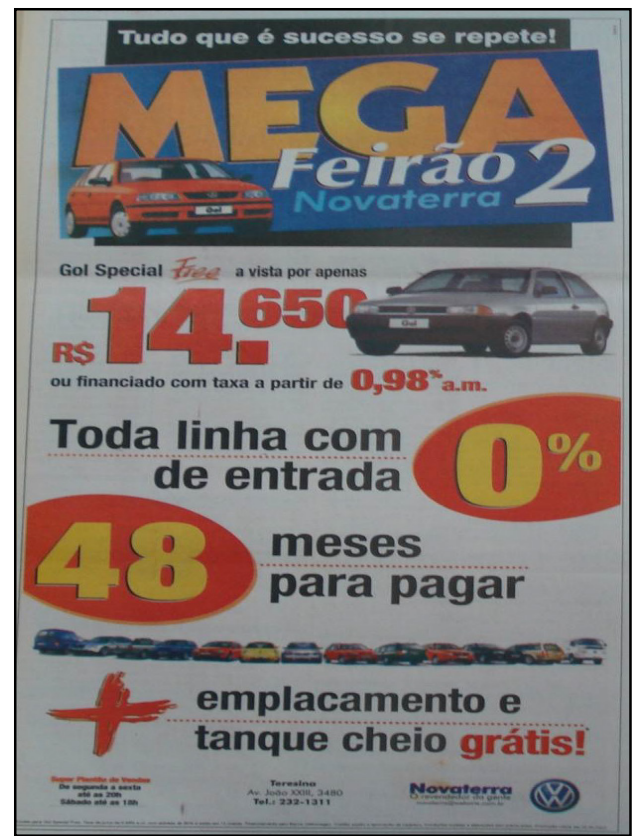

Figura 4: Anúncio de financiamento de modelos de carros Volkswagen Fonte: Jornal O Dia, 12 de maio de 2002

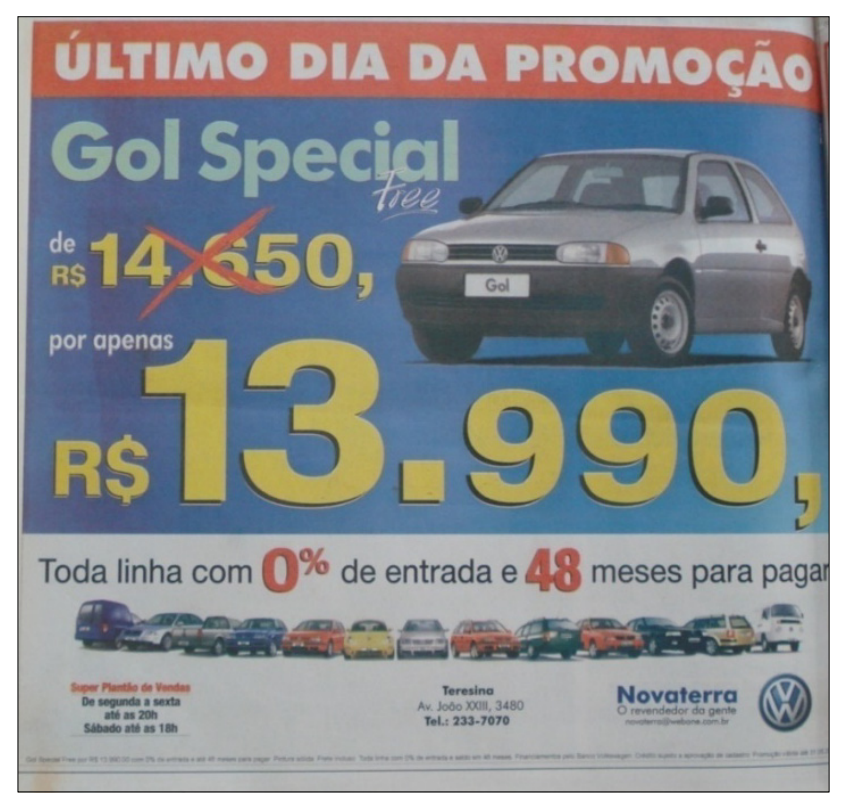

Figura 5: Anúncio Gol Special

Fonte: Jornal O Dia, 21 de maio de 2002

O leitor presumido, conforme se observou, constitui condição essencial para que o anúncio seja desenvolvido. É por meio da interpretação desse público que os desenvolvedores das mensagens poderão pensar a diagramação, a forma composicional, a disposição das imagens, entre muitos outros elementos que fazem parte desse gênero.

\section{CONDIDERAÇÕES FINAIS}

Por meio da análise dos anúncios de carros apresentados, demonstramos que o discurso elaborado para se referir ao leitor presumido mudou bastante desde o início da década de 50 até o ano de 2002. Senhor cedeu lugar a você, condições de luxo e de requinte cederam espaço para condições de financiamento. 
Isso fica ainda mais evidente quando somos levados a entender a sociedade de cada época. A princípio, década de 50, os importados no Brasil eram acessíveis a um grupo bastante seleto de indivíduos financeiramente bem dotados. Já a partir da década de 80 , a popularização dos veículos acompanha a mudança de perfil de um grupo cada vez maior e disposto a consumir carros: a classe C. Desde então, apelos mercadológicos voltados a essa classe se tornaram cada vez mais comuns.

Com isso, demonstramos que, tal como preconizado pelos autores citados no decorrer deste trabalho, os gêneros textuais constituem, de fato, construções histórico-sociais. Devido a essa condição, essas construções discursivas muito nos informam acerca da comunidade na qual foram desenvolvidos.

\section{REFERÊNCIAS}

ALVES FILHO, Francisco. Gêneros jornalísticos: notícias e cartas de leitor no ensino fundamental. São Paulo: Cortez, 2011.

. A autoria nas colunas de opinião assinadas da Folha de S. Paulo. 2005. 261 f. Tese (Doutorado em Linguística) - Instituto de Estudos da Linguagem, Universidade Estadual de Campinas, Campinas, 2005.

BAKHTIN, M. M. Estética da criação verbal. Trad. Paulo Bezerra. São Paulo: Martins Fontes, 2003 [1979]. . Marxismo e filosofia da linguagem. 14. ed. Trad.Paulo Bezerra. São Paulo: Hucitec, 1992 [1929-1930].

BAKHTIN, M. M.; VOLOSHINOV, V. N. Discourse in life and discourse in art - concerning sociological poetics. Trad. Carlos Alberto Faraco e Cristóvão Tezza. In: VOLOSHINOV, V. N. Freudism. New York: Academic Press, 1976.

BAZERMAN, C. Gêneros textuais, tipificação e interação. Organização de Ângela Paiva Dionísio e Judith Chambliss Hoffnagel. São Paulo: Cortez, 2011.

CAVALCANTE, Mônica Magalhães. Os sentidos do texto. São Paulo: Contexto, 2012.

COUTINHO, Renata Corrêa. Publicidade e propaganda: aspectos históricos. Bocc, 2011.

DEVITT, Amy. Writing genre. Southern Illinois University Press. Carbondale, 2004.

DÍAZ BORDENAVE, Juan E. O que é comunicação. São Paulo: Brasiliense, 2006.

DURANDIN, Guy. As mentiras na propaganda e na publicidade. São Paulo: JSN Editora, 1997.

ECO, U. Lector in fabula. São Paulo, Perspectiva, 1979.

FARACO, Carlos Alberto. Linguagem \& diálogo: ideias linguísticas do círculo de Bakhtin. São Paulo: Parábola Editorial, 2009.

FIORIN, José Luiz. Introdução ao pensamento de Bakhtin. São Paulo; Ática, 2008.

GOMES, Darcilene Cláudio. As ocupações de classe média: quem perdeu ao longo dos anos 90?. In: XII Congresso Brasileiro de Sociologia, 2005, Belo Horizonte. Anais XII Congresso Brasileiro de Sociologia, 2005.

MARCUSCHI, Luiz Antonio. Produção textual, análise de gêneros e compreensão. São Paulo: Parábola Editorial, 2008

MARTINS, Zeca. Propaganda é isso aí! São Paulo: Futura, 1999. 
MILLER, C. R. Gênero como ação social. In: Estudos sobre: gênero textual, agência e tecnologia. Tradução de Judith ChamblissHoffnagel et al. Recife: Ed. Universitária da UFPE, 2009. p. 21-44. [Artigo publicado originalmente em 1984].

RODRIGUES, Rosângela Hammes. Os gêneros do discurso na perspectiva dialógica da linguagem: a abordagem de Bakhtin. In: MEURER, José Luiz.; BONINI, Adair; MOTTA-ROTH, Désirée. (Org.). Gêneros: teorias, métodos e debates. São Paulo: Parábola Editorial, 2005. p.152-183.

KOCH, Ingedore V.; ELIAS, Vanda Maria. Ler e compreender os sentidos do texto. São Paulo: Contexto, 2006.

Recebido em 30 / 07 / 2014. Aprovado em 20 / 05 / 2015. 